\title{
Modification of Lithium Metal Anode and Solid-State Electrolyte Interface with a Gel Electrolyte
}

\author{
Lawrence A. Renna, ${ }^{1}$ Francois-Guillame Blanc, ${ }^{1,2}$ Vincent Giordani ${ }^{1}$ \\ ${ }^{1}$ Battery Systems, Fisker Inc., Los Angeles, CA \\ ${ }^{2}$ Université Clermont Awvergne, CNRS, SIGMA Clermont, Institut Pascal, Clermont-Ferrand, F-63000, France
}

\begin{abstract}
:
Solid-state electrolytes are continually being explored for Li-ion batteries due to their enhanced safety and their enabling of high energy density active materials, particularly Li metal anodes. However, the interface between solid-state electrolytes and Li metal anodes are prone to high impedance due to poor contact, limiting their applicability. Introducing a thin gel polymer electrolyte interlayer to conformally coat solid electrolytes can improve the interfacial contact of $\mathrm{Li}$ metal anode and thus reduce the interfacial resistance. Here we used a plasticized poly(ethylene oxide)-based electrolyte with high concentrations of bis(trifluoromethane)sulfonamide lithium (LiTFSI) that show 100\% amorphous character. These electrolytes show $\mathrm{Li}^{+}$conductivity as high as $\sigma$ $=2.9 \times 10^{-4} \mathrm{~S} / \mathrm{cm}$ at room temperature. We discovered by thermogravimetric analysis (TGA) with off-gas analysis in conjunction with nuclear magnetic resonance (NMR) spectroscopy that the electrolyte films had absorbed N-methyl-2-pyrrolidone (NMP) vapors to form a gel electrolyte. We incorporated the gel electrolyte as an interfacial modification layer between LLZO and Li metal electrodes and found a 58 times reduction in the area specific resistance (ASR) at room temperature.
\end{abstract}

\section{Introduction:}

Rechargeable Lithium-ion batteries have matured significantly in the last few decades. ${ }^{1-3}$ While lithium metal has the highest specific capacity $(3860 \mathrm{mAh} / \mathrm{g})$ and the lowest electrochemical potential $(-3.04 \mathrm{~V}$ vs standard hydrogen electrode) in comparison to any other battery anode materials, its use in rechargeable cells has been hindered by formation of metal dendrites in liquid electrolyte systems that can penetrate commercial plastic separators and cause both safety concerns and performance decay in long-term cycling applications.4-6 "Beyond Lithium-ion" chemistries such as all-solid-state, Lithium/Sulfur and Lithium/ $\mathrm{O}_{2}$ batteries have received a great deal of interest over the past decade ${ }^{6-11}$ due to their high theoretical energy densities, far exceeding those of commercial Lithium-ion cells.

Interest in all-solid-state Lithium batteries with better safety has stimulated research on solid $\mathrm{Li}^{+}$-based electrolytes. ${ }^{12}$ Lithium Lanthanum Zirconium Oxide $\mathrm{Li}_{7} \mathrm{La}_{3} \mathrm{Zr}_{2} \mathrm{O}_{12}$ (LLZO) derived garnet electrolytes, which have a $\mathrm{Li}^{+}$ionic conductivity of $10^{-4} \mathrm{~S} / \mathrm{cm}$ at $25^{\circ} \mathrm{C}$, wide electrochemical stability window $(0-5 \mathrm{~V})$, and better stability versus $\mathrm{Li}$ metal than the other ceramic electrolytes, ${ }^{13-15}$ face two great challenges: 1) a large interfacial resistance for lithium deposition/dissolution during battery cycling $\left(>10^{3}\right.$ $\mathrm{ohm} \mathrm{cm}^{2}$ ), and 2) lithium dendrite penetration along the ceramic electrolyte grain boundaries. ${ }^{16-18}$ One reason for the high interfacial resistance is the poor contact between LLZO and lithium metal anode, as both materials are hard solids, which in turn leads to poor rate capability, low power density and limited cycle life at practical current densities. ${ }^{16}$

Current efforts to reduce the interfacial resistance for solid $\mathrm{Li}^{+}$electrolytes mainly focus on introducing interfacial layers such as metals/metal oxides (e.g. $\mathrm{Mg}, \mathrm{Au}$, and $\left.\mathrm{Al}_{2} \mathrm{O}_{3}\right),{ }^{19}$ dry polymers between electrolyte and lithium metal anode (e.g. PEO, PAN, and PVDF), ${ }^{20,21}$ which are effective but require elevated temperatures for formation and battery electrochemical cycling, respectively. Other research groups have developed a porous-dense bilayer structured solid electrolyte as a 3D ionic framework for $\mathrm{Li}$ metal. The framework consists of one porous LLZO layer as a volume-stable host of $\mathrm{Li}$ metal with a large contact area, and one dense LLZO layer as a solid-state separator preventing short-circuits. ${ }^{22-24}$ Alternatively, gel electrolyte interlayers, composed of polymer and liquid electrolyte, are more scalable for solid-state battery manufacturing. The flexible and soft gel interface layer enables continuous contact between LLZO and lithium metal, while the high $\mathrm{Li}^{+}$ionic conductivity of the gel at room temperature adds negligible bulk resistance to the battery. ${ }^{22,25}$

In this work, we have fabricated poly(ethylene oxide) (PEO) electrolytes with high concentrations of bis(trifluoromethane)sulfonamide lithium (LiTFSI) that show $100 \%$ amorphous character. These materials show $\mathrm{Li}^{+}$ conductivity as high as $\sigma=2.9 \times 10^{-4} \mathrm{~S} / \mathrm{cm}$ at room temperature. The electrolyte films were on the order of 10 $\mu \mathrm{m}$. We discovered by thermogravimetric analysis (TGA) with off-gas analysis in conjunction with nuclear magnetic resonance (NMR) spectroscopy that the electrolyte films 
had absorbed $N$-methyl-2-pyrrolidone (NMP) vapors creating a gel electrolyte. We incorporated the gel electrolyte as an interfacial modification layer between LLZO and Li metal electrodes. We found that the room temperature interfacial areas specific resistance (ASR) decreased from $765.0 \mathrm{kohm} \mathrm{cm}{ }^{2}$ without modification to $13.05 \mathrm{kohm} \mathrm{cm}{ }^{2}$ with interface modification, a 58 times reduction in ASR.

\section{Experimental:}

Film Preparation.- PEO $\left(\mathrm{M}_{\mathrm{V}}=600,000\right.$, SigmaAldrich) and LiTFSI (99\%, Acros Organics) were first dried in vaccuo for 3 days at $45^{\circ} \mathrm{C}$ and $150^{\circ} \mathrm{C}$, respectively. Polymer films were prepared in an Ar-filled glovebox, with both $\mathrm{O}_{2}$ and $\mathrm{H}_{2} \mathrm{O}$ levels maintained below $10 \mathrm{ppm}$, by dissolving PEO in Acetonitrile (99.5\%, anhydrous, Sigma-Aldrich) with the corresponding amount of LiTFSI at total solids loadings varying from $11.9 \mathrm{wt} . \%$ to $22.6 \mathrm{wt} . \%$ depending upon the $\mathrm{EO}$ to $\mathrm{Li}^{+}$molar ratio. In this study, we used three different $\mathrm{EO} / \mathrm{Li}^{+}$molar ratios, namely 30:1, 10:1, and 4:1. Polymer solutions were mixed on a magnetic stir plate using a magnetic stir bar for $\sim 24 \mathrm{hr}$. Polymer solutions were cast on silicone-coated biaxially-oriented polyethylene terephthalate (Mylar $($ ) $)$ using a doctor blade with a gap height of $0.2 \mathrm{~mm}$. Films were dried in Ar for $\sim 2 \mathrm{hr}$ and then in vaccuo at $\sim 100^{\circ} \mathrm{C}$ for $\sim 18 \mathrm{hr}$. All films were stored under argon.

Characterization.- PEO:LiTFSI films were transfer coated to glass microscope slides, optical microscopy was performed using a Dual-View Compound Microscope equipped with a $4 \times$ objective and a digital camera (AmScope); image analysis was performed using ImageJ. Xray diffraction (XRD) was performed using a Rigaku SmartLab X-ray diffractometer with $\mathrm{Cu} \mathrm{K}_{\alpha}(1.54 \AA)$ at 40 $\mathrm{kW}$ and $44 \mathrm{~mA}$ in $\theta / 2 \theta$ scanning mode, with 0.02 step size, with a $\mathrm{K}_{\beta} \mathrm{Ni}$ filter, and with a $1 \mathrm{D} \mathrm{D} / \mathrm{teX}$ Ultra high-speed silicon strip detector. Differential scanning calorimetry (DSC) was performed using a Netzsch Polyma DSC 214; samples were placed in pierced $\mathrm{Al}$ pans. Thermogravimetric analysis (TGA) was performed with the Netzsch STA 449 F1 Jupiter ${ }^{\circledR}$ with off-gas mass spectrometry (MS) using a Netasch QMS 403 Aëolos Quadro and Fourier transform infrared (FTIR) spectroscopy with a Bruker FTIR; samples were placed in alumina crucibles and measurements were made under a $\mathrm{N}_{2}$ environment. For NMR analysis, polymer electrolytes were sonicated in $\mathrm{D}_{2} \mathrm{O}$, and measurements were conducted using a $600 \mathrm{MHz}$ Bruker Avance spectrometer.

Cell Assembly. - Symmetric cells were fabricated in an Ar-filled glovebox by transfer-coating the PEO:LiTFSI film from the Mylar to a stainless steel disk with radius of $0.8 \mathrm{~cm}$ for blocking electrode experiments. An additional stainless steel electrode was applied to the top of the
PEO:LiTFSI film. The symmetric cell was placed inside an alligator coin cell clip for conductivity testing. For $\mathrm{Li} / \mathrm{Li}$ symmetric cells, PEO:LiTFSI film was directly transfercoated to Li metal foil disk (100 $\mu \mathrm{m}$ thick, MTI corporation) with a radius of $0.4 \mathrm{~cm}$. Two coated $\mathrm{Li}$ foils were then assembled between stainless steel disks and put into a split cell for testing (MTI Corporation). Nb-doped LLZO pellets $(0.8 \mathrm{~cm}$ diameter) with $>1 \%$ proprietary glassy phases were obtained courtesy of Schott AG, Research and Development. LLZO pellets were assembled between two $\mathrm{Li}$ metal anodes which were transfer-coated with the polymer electrolyte.

Cell Testing.- Conductivity was measured by performing potentiostatic electrochemical impedance spectroscopy (EIS) using an Ivium Vertex.One instrument with Impedance Analyzer with $V_{\mathrm{AC}}=10 \mathrm{mV}, V_{\mathrm{DC}}=0 \mathrm{mV}$ vs open circuit potential $\left(E_{\mathrm{OC}}\right)$ at frequency range $f=0.2$ $\mathrm{MHz}$ to $0.01 \mathrm{~Hz}$, with a spacing of 10 points per decade. Equivalent circuit (EC) modeling was performed using the impedance.py package in Python3. ${ }^{26} \mathrm{Li} / \mathrm{Li}$ symmetric cell cycling was performed on Arbin Instruments BT-2000 galvanostat at $55^{\circ} \mathrm{C}$ using a $0.05 \mathrm{~mA} / \mathrm{cm}^{2}$ current density.

\section{Results and Discussion:}

Characterization of PEO:LiTFSI films. - Fig. 1a and $1 \mathrm{~b}$ show optical micrographs of PEO film without added salt and with a EO:LiTFSI molar ratio of $4: 1$, respectively. It is evident that when no salt is added to the PEO large crystalline domains and phase separation are present. However, at EO:LiTFSI of 4:1 there are no visible crystalline domains by optical microscopy, and the film morphology is relatively homogeneous. Fig. 1c shows the normalized integrated intensity vs radius for the radial average of the Fourier transform of the binarized optical micrographs. For PEO with no added salt there is a distinct peak that spans $16 \mu \mathrm{m}$ to $26 \mu \mathrm{m}$, representative of the correlation length of crystalline domains or grains in the film. There is no such defined peak for the film with EO:LiTFSI of 4:1. These results indicate that the addition of LiTFSI in the PEO disturbs the crystalline packing of the polymer and encourages an amorphous morphology.

XRD was performed on PEO films with no salt added and with EO:LiTFSI of 30:1, 10:1, and 4:1, shown in Fig. $1 \mathrm{~d}$. Refence peak positions and relative intensities for PEO and LiTFSI are shown in black and grey respectively. For pure PEO and EO:LiTFSI of 30:1 there are clear crystalline diffraction peaks at $2 \theta \sim 19^{\circ}$ and $23^{\circ}$. The average crystallite size $(\tau)$ was estimated for these samples using the Scherrer equation (Eq. 1): 


$$
\tau=\frac{K \lambda}{\beta \cos \theta}
$$

where $\boldsymbol{K}$ is a dimensionless shape factor taken at $0.9, \beta$ is the full width at half the maximum intensity of the strongest intensity peak, and $\theta$ is the Bragg angle. Pure PEO had a $\tau$ $=25.64 \mathrm{~nm}$, and EO:LiTFSI of 30:1 had a $\tau=18.95 \mathrm{~nm}$.

a)

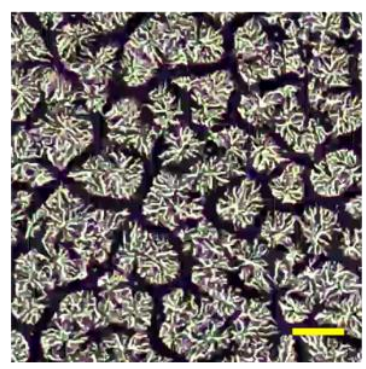

c)

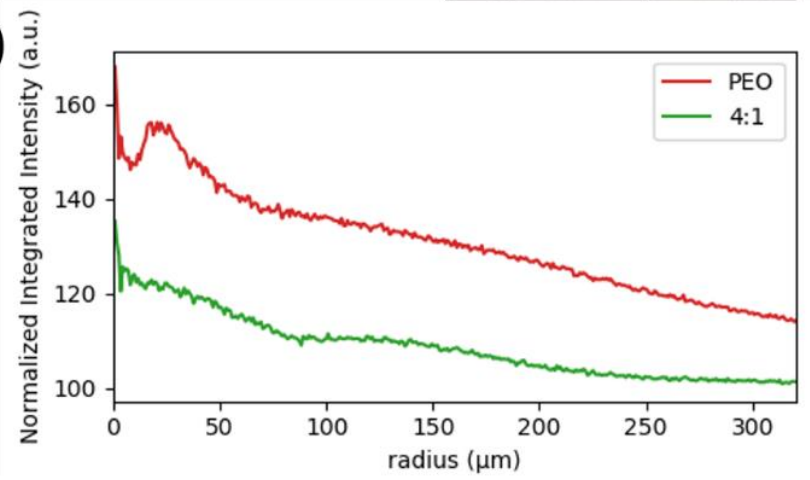

e)

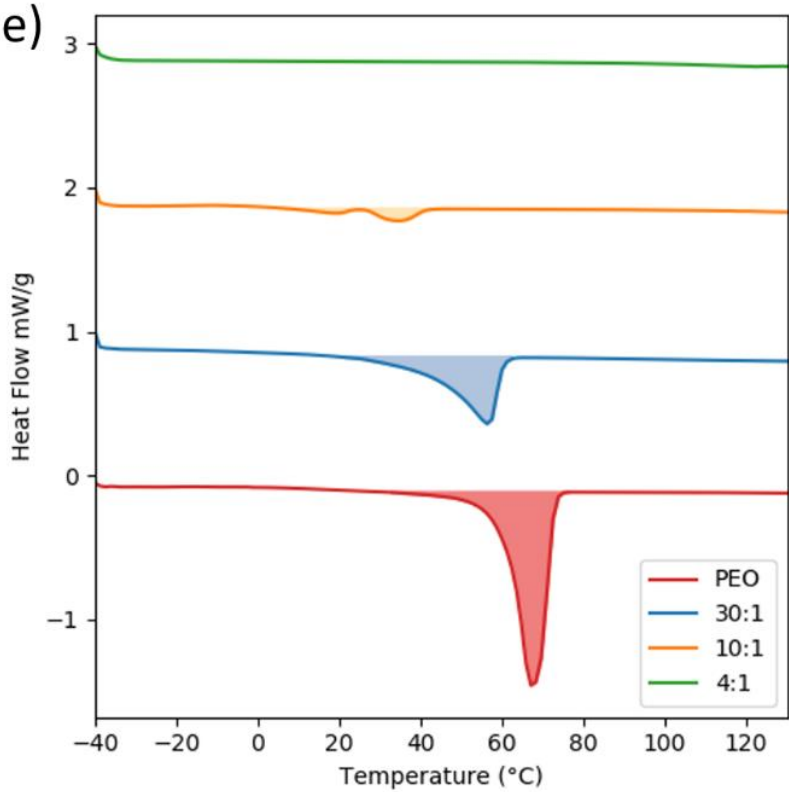

These results support the hypothesis that addition of LiTFSI disrupts the crystalline packing of PEO resulting in smaller crystallites. For samples with EO:LiTFSI of 10:1 and 4:1 two amorphous humps appear and there are nocrystalline peaks associated with PEO or LiTFSI. The amorphous peaks are actually enhanced for samples with

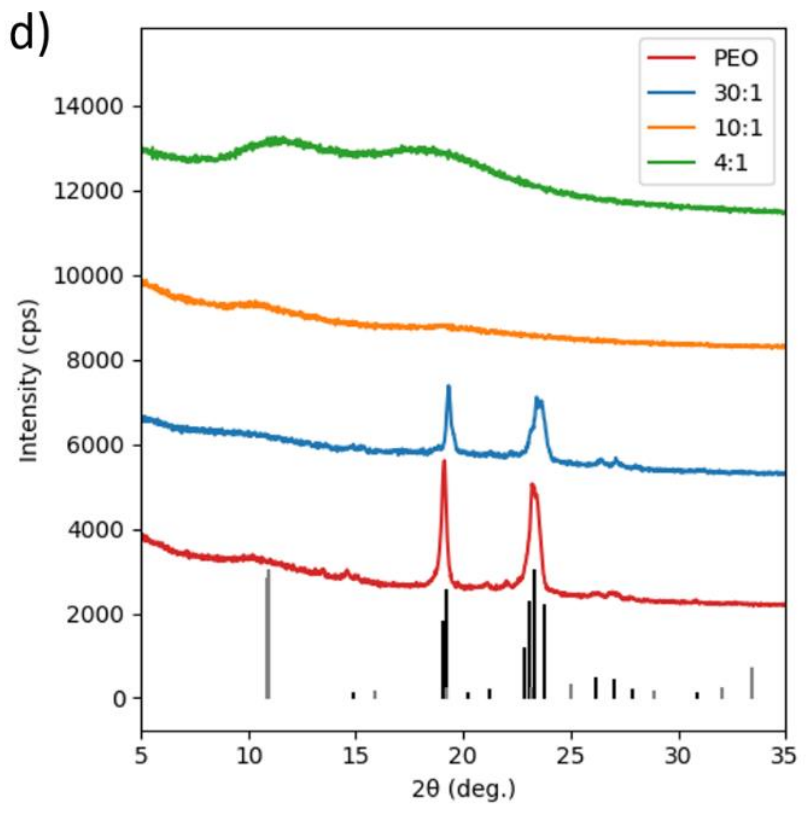

f)

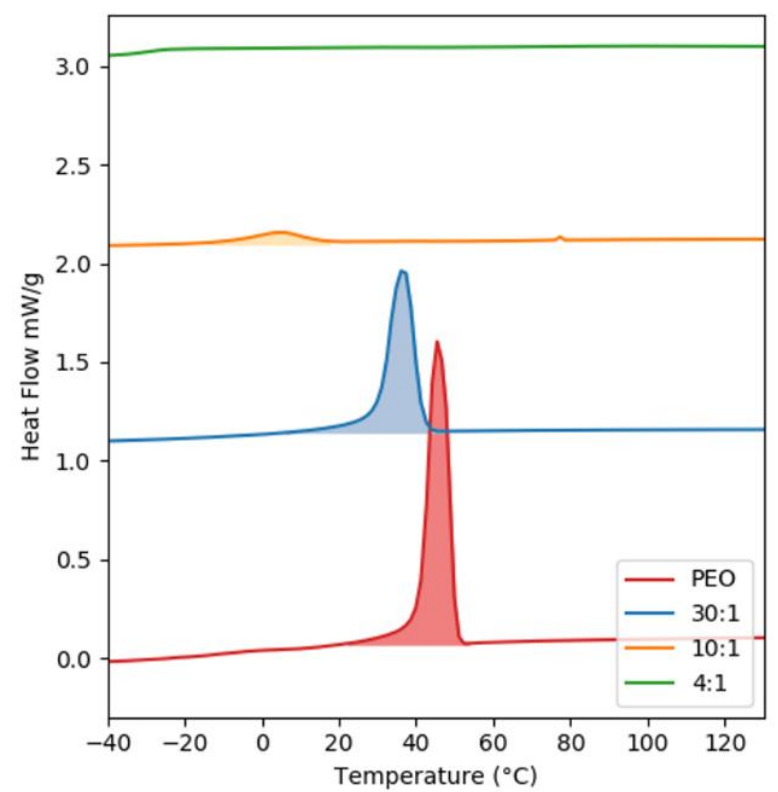

Figure 1: Optical micrographs of PEO films with (a) no added salt, and (b) with EO:LiTFSI of 4:1; scale bar is 500 $\mu \mathrm{m}$. (c) Normalized integrated intensity vs radius for the radial average of the Fourier transform of a binarized optical micrographs. (d) XRD of PEO films with no salt added and with EO:LiTFSI of 30:1, 10:1, and 4:1. Refence peak positions and relative intensities for PEO and LiTFSI are shown in black and grey respectively. DSC (e) melting and (f) crystallization curves of PEO films with no salt added and with EO:LiTFSI of 30:1, 10:1, and 4:1. 
EO:LiTFSI of 4:1. The strongest diffraction peak for LiTFSI is at $2 \theta \sim 10^{\circ}$ indicating that at all concentrations the salt is well-solubilized in the polymer matrix. These results show that within the detection limit of the XRD measurement, a EO:LiTFSI of 10:1 is sufficient to disrupt the crystalline packing of PEO.

Fig. 1e and 1f show the melting and crystallizing DSC curves respectively, for PEO films with no salt added and with EO:LiTFSI of 30:1, 10:1, and 4:1. Pure PEO showed a melting endothermic peak at $67.5^{\circ} \mathrm{C}$ with an area of -141.1 $\mathrm{J} / \mathrm{g}$ and a crystallizing exothermic peak at $45.5^{\circ} \mathrm{C}$ with an area of $113.3 \mathrm{~J} / \mathrm{g}$. The sample with EO:LiTFSI of 30:1 showed a melting endothermic peak at $55.7^{\circ} \mathrm{C}$ with an area of $-70.25 \mathrm{~J} / \mathrm{g}$ and a crystallizing exothermic peak at $38.1^{\circ} \mathrm{C}$ with an area of $76.57 \mathrm{~J} / \mathrm{g}$. The sample with EO:LiTFSI of 10:1 showed a melting endothermic peak at $34.2^{\circ} \mathrm{C}$ with an area of $-9.09 \mathrm{~J} / \mathrm{g}$ and a crystallizing exothermic peak at $5.3^{\circ} \mathrm{C}$ with an area of $8.94 \mathrm{~J} / \mathrm{g}$, there is an additional small secondary melting peak at $18.9^{\circ} \mathrm{C}$ attributable to the melting of PEO domains not coordinated with salt ions. For the sample with EO:LiTFSI of 4:1, there were no measurable melting of crystallization peaks. The degree of crystallinity $\left(\chi_{c}\right)$ was calculated by Eq. 2:

$$
\chi_{c}=\frac{\Delta H_{m}}{\Delta H_{m}^{\circ}} 100 \%
$$

where $\Delta H_{m}$ is the enthalpy of melting, and $\Delta H_{m}^{\circ}$ is the melting enthalpy for $100 \%$ crystalline PEO, taken at 203 $\mathrm{J} / \mathrm{g} .{ }^{27}$ The degree of crystallinity was calculated to be $\chi_{c}=$ $70 \%, \chi_{c}=35 \%, \chi_{c}=4 \%$, and $\chi_{c}=0 \%$ for pure PEO, and with EO:LiTFSI of 30:1, 10:1, and 4:1 respectively. These results show how the addition of LiTFSI to PEO reduces the crystallinity, and with EO:LiTFSI of 4:1 the material is completely amorphous, within the detection limits of DSC.

Conductivity of PEO:LiTFSI films. - Blocking electrode symmetric cells for samples with EO:LiTFSI of 30:1, 10:1, and 4:1 were fabricated with stainless steel electrodes for conductivity measurements by EIS. All impedance measurements were recorded at room temperature (i.e. $\sim 25^{\circ} \mathrm{C}$ ) inside an Ar-filled glovebox. Fig. 2a shows the Nyquist plots where the real component of the impedance $\left(Z^{\prime}\right)$ is plotted as the abscissa and the imaginary part ( $\left.Z^{\prime \prime}\right)$ as the ordinate. Fig $2 \mathrm{~b}$ shows the Bode plots where Z' is one abscissa and the phase-shift is plotted as the other against the frequency as the ordinate. Samples with a EO:LiTFSI of 30:1 show a high-frequency semi-circle followed by linear feature due to the blocking nature of the electrodes. As more LiTFSI is added to the PEO from EO:LiTFSI of 30:1 to 10:1 to 4:1, the graph shifts down the $\mathrm{x}$-axis (Z') of the Nyquist plot (Fig 2a) towards lower values, indicating a decrease in the resistance. The decrease in resistance is also obvious in the Bode plot (Fig. 2b) by looking at the decrease in the real impedance at high frequencies. The semicircle is attributed to bulk resistance and capacitance associated with the polymer film. Samples with a EO:LiTFSI of 10:1 show a partial semicircle, this appears at slightly higher frequencies than EO:LiTFSI of 30:1, evident in the inflection of the phase angle at high frequency in the Bode plot in Fig. 2b. Samples with a EO:LiTFSI of $4: 1$ did not display a semicircle due to the high conductivity.

EIS spectra were fit with an equivalent circuit (EC) model shown in Fig. 2C, where $\mathrm{R}_{\mathrm{S}}$ is the series resistance, $\mathrm{R}_{\mathrm{b}}$ is the bulk polymer resistance, $\mathrm{CPE}_{\mathrm{b}}$ is a constant phase element (CPE) which accounts for the bulk capacitance of the polymer film (a CPE is used instead of a standard capacitor to account for the time-constant heterogeneity due to inhomogeneity in the sample), and $\mathrm{CPE}_{\text {int }}$ accounts for the capacitance associated with the blocking electrodes at low frequencies. The results of the EC model fits to the data are shown as black dashed lines in Fig. $2 \mathrm{a}$ and $2 \mathrm{~b}$ and show good agreement with the experimental data. When there is no semi-circle present in the experimental data, as in samples with EO:LiTFSI of 4:1, the fitted value CPE int is sufficiently high to effectively short circuit the capacitor at high frequencies, yielding an equivalent circuit that is simple circuit of a resistor in series with $\mathrm{CPE}_{\text {int. }}$. The conductivity $(\sigma)$ of the PEO:LiTFSI samples was calculated using Eq. 3:

$$
\sigma=\frac{l}{\mathrm{R}_{\mathrm{b}} A}
$$

where $l$ is the thickness of the sample, $\mathrm{R}_{\mathrm{b}}$ is the EC model fitted bulk resistance of the sample, and $A$ is the area. The results of conductivity vs EO:LiTFSI are shown in Fig.2d showing an up to three order of magnitude increase in conductivity from EO:LiTFSI of 30:1 to 4:1. The maximum room temperature $\mathrm{Li}^{+}$ionic conductivity measured for samples with an EO:LiTFSI of 30:1, 10:1, and 4:1 were $\sigma=$ $4.3 \times 10^{-7}, \sigma=6.6 \times 10^{-6}$, and $\sigma=2.9 \times 10^{-4} \mathrm{~S} / \mathrm{cm}$, respectively. This is a very high conductivity for a polymer electrolyte at room temperature. The complex impedance ( $\mathrm{Z}$ ) of a constant phase element is calculated by Eq. 4:

$$
Z=\frac{1}{\left[Q(j \omega)^{\alpha}\right]}
$$

where $Q$ is the admittance with units of $\Omega^{-1} \mathrm{~s}^{\alpha}, j$ is $\sqrt{-1}, \omega$ is the radial frequency, and $\alpha$ is unitless exponent which describes how non-perfect the capacitor is. The pseudocapacitance of a CPE can be calculated by Eq. 5:

$\mathrm{C}=\frac{(Q \mathrm{R})^{1 / \alpha}}{\mathrm{R}}$ 
where $\mathrm{R}$ is the resistor in parallel with the CPE. For samples with EO:LiTFSI of 30:1, 10:1 the capacitance was $C=0.42$ $\mathrm{nF}$ and $\mathrm{C}=0.30 \mathrm{nF}$ respectively.

Temperature-dependent conductivity measurements were performed on a sample with a EO:LiTFSI of 4:1 in order to calculate the activation energy $\left(E_{A}\right)$ for lithium ion transport in the film. A plot of the logarithm of conductivity

a)

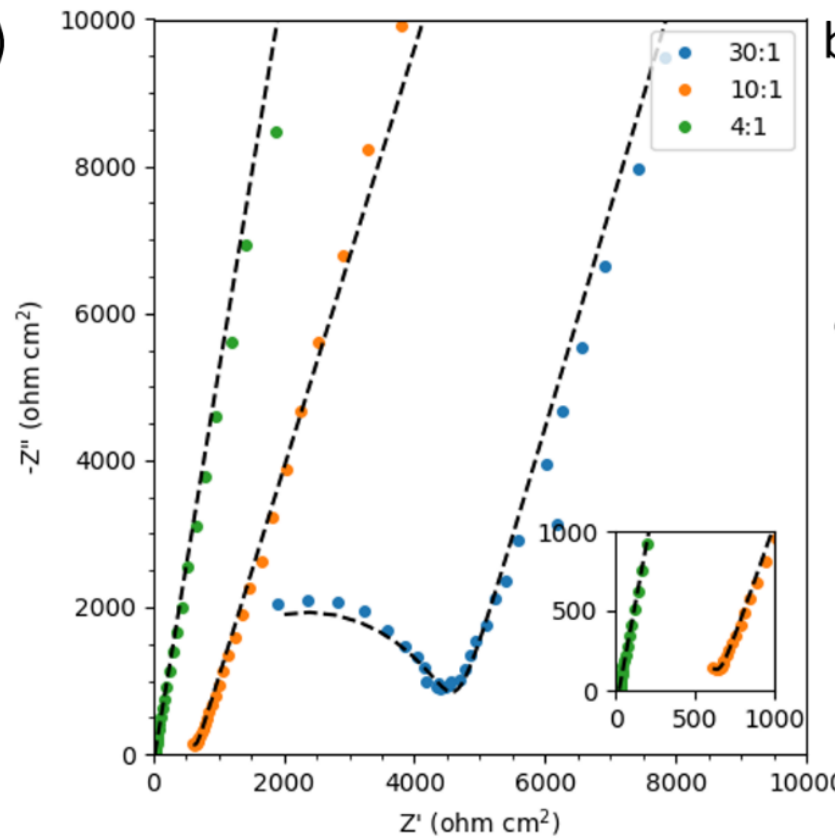

vs $1000 / \mathrm{T}$ is shown in Fig. 2e, where the data shows a nonlinear dependence indicating that a classical Arrhenius dependence is not appropriate. Thus, the data was fit with the Vogel-Tammann-Fulcher (VTF) equation. Based on the work by McCloskey and co-workers we used two different version of the VTF equation, VTF1 (Eq. 6) and VTF2 (Eq. 7):28

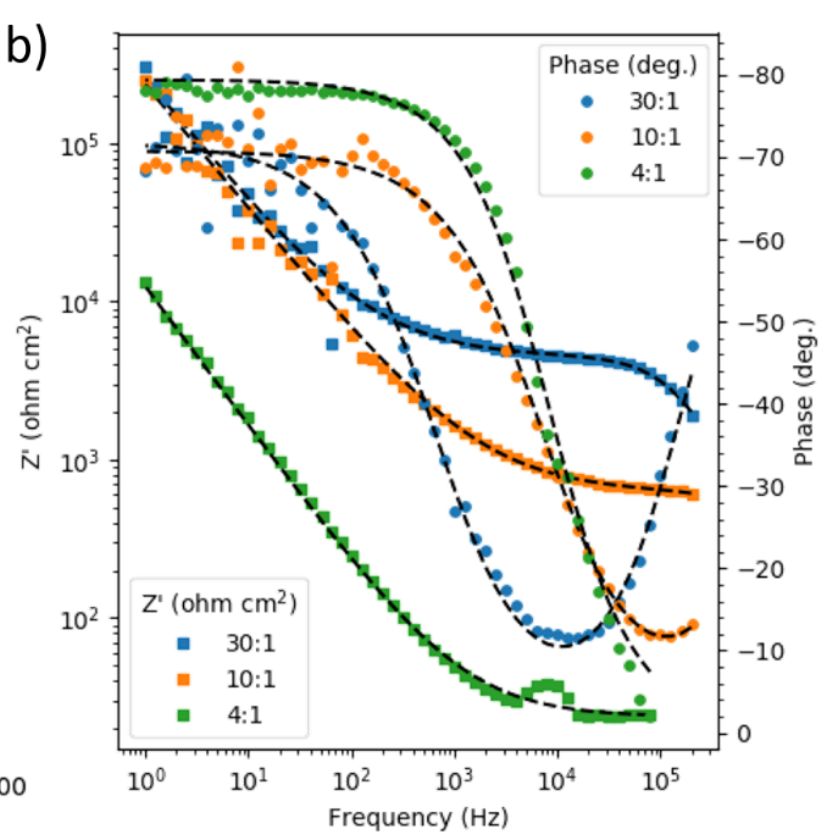

c)

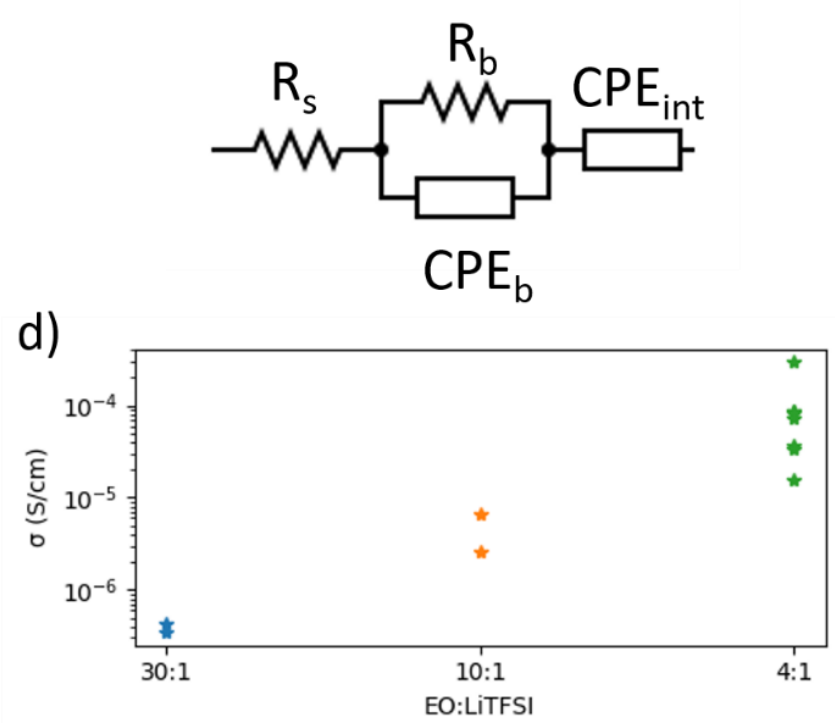

e)

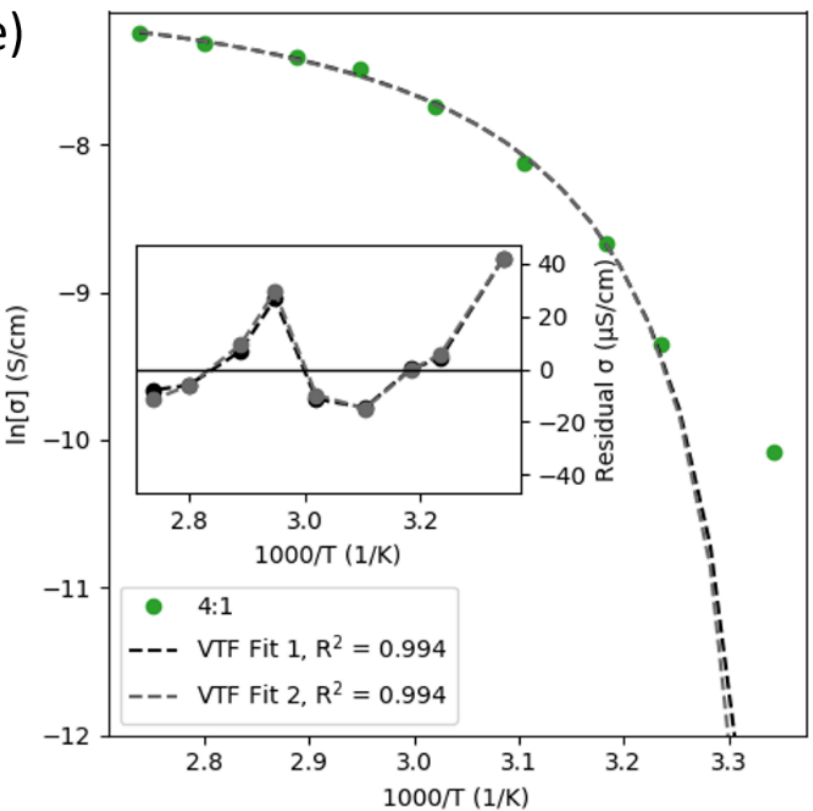

Figure 2: Nyquist plots and (b) Bode plots of EIS results for samples with an EO:LiTFSI of 30:1, 10:1, and 4:1. (c) Equivalent circuit model used to fit EIS data. (d) Plot of electrolyte conductivity vs. EO:LiTFSI. (e) Plot of the log of electrolyte conductivity vs inverse of temperature with corresponding VTF fits; inset shows residual error from fitting. 


$$
\begin{aligned}
& \sigma=A T^{-1 / 2} \exp \left(-\frac{E_{A}}{R\left(T-T_{0}\right)}\right) \quad(\mathrm{VTF} 1) \\
& \sigma=A \exp \left(-\frac{E_{A}}{R\left(T-T_{0}\right)}\right) \quad(\mathrm{VTF} 2)
\end{aligned}
$$

where $A$ is prefactor with units of $\mathrm{S} / \mathrm{cm}, T$ is temperature in Kelvin, and $T_{0}$ is the Vogel temperature, which is the glass transition temperature of an ideal glass. Fits of the data using least squares regression with equations VTF1 and VTF2 are shown in Fig. 2e in black and grey dashed lines respectively. The residual error in the conductivity is plotted vs temperature are plotted in the inset of Fig 2e. The coefficient of determination was $\mathrm{R}^{2}=0.994$ for both fits of VTF1 and VTF2, consistent with previous work which showed that the two equations yield the same quality of fit.28 VTF1 yielded values of $A=0.024 \mathrm{~S} / \mathrm{cm}, E_{A}=327.74$ $\mathrm{J} / \mathrm{mol}$, and $T_{0}=295.11 \mathrm{~K}$. VTF2 yielded values of $A=$ $0.0012 \mathrm{~S} / \mathrm{cm}, E_{A}=288.53 \mathrm{~J} / \mathrm{mol}$, and $T_{0}=296.24 \mathrm{~K}$. The fitted values from VTF2 are consistent with literature values for other PEO:LiTFSI films. ${ }^{28} E_{A}$ values for EO:LiTFSI of 4:1 are comparable to that of LiTFSI in liquid DMSO.

Origin of High Conductivity.- The origin of the completely amorphous polymer structure and abnormally high conductivity of PEO:LiTFSI films was initially unknown. Inspired by literature examples of strong interactions between LiTFSI and solvents ${ }^{29}$ such as acetonitrile which could result in residual solvent in electrolytes $^{30}$ and can provide a plasticizing affect, we sought to explore if a similar phenomenon was occurring in these films. To investigate this, we performed TGA with off-gas analysis by mass spectrometry and FTIR. The TGA results for a film with EO:LiTFSI of 4:1 is shown in Fig. 3 a. The TGA indicates a mass loss of $\sim 2 \%$ from $40^{\circ} \mathrm{C}$ to $110^{\circ} \mathrm{C}$ and an additional $30 \%$ mass loss from up to $300^{\circ} \mathrm{C}$. TGA results for a film with EO:LiTFSI of 30:1 showed a total mass loss of only $10 \%$ (Fig. S1), which indicates that the amount of LiTFSI plays a critical role in the amount of volatile species that is present in the film. TGA of PEO did not show mass loss (Fig. S2), whereas LiTFSI (Fig. S3) absorbed water from the atmosphere prior to TGA and showed a mass loss from $40^{\circ} \mathrm{C}$ to $140^{\circ} \mathrm{C}$. Thus the initial $2 \%$ mass loss from the film with EO:LiTFSI of $4: 1$ was likely due to absorbed water during the measurement setup. The additional 30\% mass loss was thus due to some volatile species in the electrolyte. We analyzed the off-gas from the TGA experiments by MS (Fig. 3b-c) and FTIR (Fig. 3d). The analog scan MS showed evolution of peaks at $70^{\circ} \mathrm{C}$ that were not present in the empty crucible, PEO only, LiTFSI only, or a sample with EO:LiTFSI of to 4:1 that was handground by mortar and pestle without solvent (Fig. S4). The transient profiles of selected peaks $(\mathrm{m} / \mathrm{z})$ are shown in Fig. 3c. Off-gas analysis by FTIR is shown in Fig. 3d and shows the evolution of a strong peak at $1735 \mathrm{~cm}^{-1}$ and a less intense broad peak at $2899 \mathrm{~cm}^{-1}$, indicative of $\mathrm{C}=\mathrm{O}$ stretching and $\mathrm{C}-\mathrm{H}$ stretching respectively. Additional peaks at $1416 \mathrm{~cm}^{-1}$ and $1275 \mathrm{~cm}^{-1}$ were also present. The observed peaks suggest the presence of $\mathrm{N}$-methyl-2-pyrrolidone (NMP) based on NIST standard. ${ }^{31}$ When comparing the analog MS scan to the NIST mass spectrum for NMP (black bars in Fig. 3b), ${ }^{31}$ there is high correlation, again indicating the presence of NMP. TGA-MS analysis of a film with EO:LiTFSI of to 30:1 is shown in Fig. S1. This sample showed only a $9.6 \%$ mass loss with a mass loss over a shorter temperature window. The peaks in the mass spectrum also indicate the loss of NMP during the TGA experiment. Thus, the sample with less LiTFSI contained less NMP than the sample with EO:LiTFSI of 4:1.

Finally, we prepared a film with EO:LiTFSI of 4:1 in $\mathrm{D}_{2} \mathrm{O}(23 \mathrm{mg} / \mathrm{mL})$ and sonicated to help dissolution for NMR analysis. The ${ }^{1} \mathrm{H}$ NMR spectrum is shown in Fig. 3e. The NMR spectrum was: ${ }^{1} \mathrm{H}$ NMR $\left(600 \mathrm{MHz}, \mathrm{D}_{2} \mathrm{O}\right) \delta 3.72$ (s, $7.37 \mathrm{H}), 3.51(\mathrm{t}, 2 \mathrm{H}, J=7.3 \mathrm{~Hz}), 2.84(\mathrm{~s}, 3 \mathrm{H}), 2.43$ (t, 2 $\mathrm{H}, J=8.2 \mathrm{~Hz}), 2.05(\mathrm{~m}, 2 \mathrm{H}, J=7.7 \mathrm{~Hz}), 2.05(\mathrm{~s}, 0.125 \mathrm{H}) ; 32$ the $\mathrm{H}_{2} \mathrm{O}$ peak at $4.79 \mathrm{ppm}$ was ignored. There is a large, broadened peak (peak a) at $3.72 \mathrm{ppm}$ which integrates to $\sim 7.37 \mathrm{H}$ which is attributed to protons in the EO repeat unit. There is an apparent triplet (peak b) at $3.51 \mathrm{ppm}$ which integrates to $2 \mathrm{H}$ which is attributed to the $\mathrm{CH}_{2}$ of NMP next to the nitrogen. There is a singlet (peak c) at $2.83 \mathrm{ppm}$ which integrates to $3 \mathrm{H}$ is attributed to the $\mathrm{N}$-methyl group of NMP. There is another apparent triplet (peak d) at 2.43 ppm which integrates to $2 \mathrm{H}$ is attributed to the $\mathrm{CH}_{2}$ next to the carbonyl of NMP. There is a multiplet (peak e) at 2.05 ppm which integrates to $2 \mathrm{H}$ and is attributed to the $\mathrm{CH}_{2}$ of NMP between two other $\mathrm{CH}_{2}$ groups. Finally, there is a singlet (peak f) at $2.01 \mathrm{ppm}$ which integrates to $1 / 8 \mathrm{H}$ is attributed to the methyl group from residual acetonitrile.

NMP is a commonly used solvent in the glovebox where the polymer films were prepared. Although no direct contamination occurred, NMP vapors present in the glovebox were still incorporated into the film. The more LiTFSI that was added to the electrolyte the more NMP was incorporated. Thus, there is likely strong ion-solvent interactions which caused NMP incorporation and prevented it from being evaporated during film drying under heat and vacuum. Further, residual acetonitrile was also observed in the film due to strong ion-solvent interactions. Gel polymer electrolytes using NMP and polyvinyl alcohol (PVA) and a lithium salt have been reported for $\mathrm{Li}^{+}$conductivity. ${ }^{33} \mathrm{Ek}$ et al. demonstrated the "necessity" of residual solvent dimethyl sulfoxide (DMSO) in PVA:LiTFSI electrolytes for $\mathrm{Li}^{+}$ionic transport. ${ }^{34} \mathrm{In}$ 

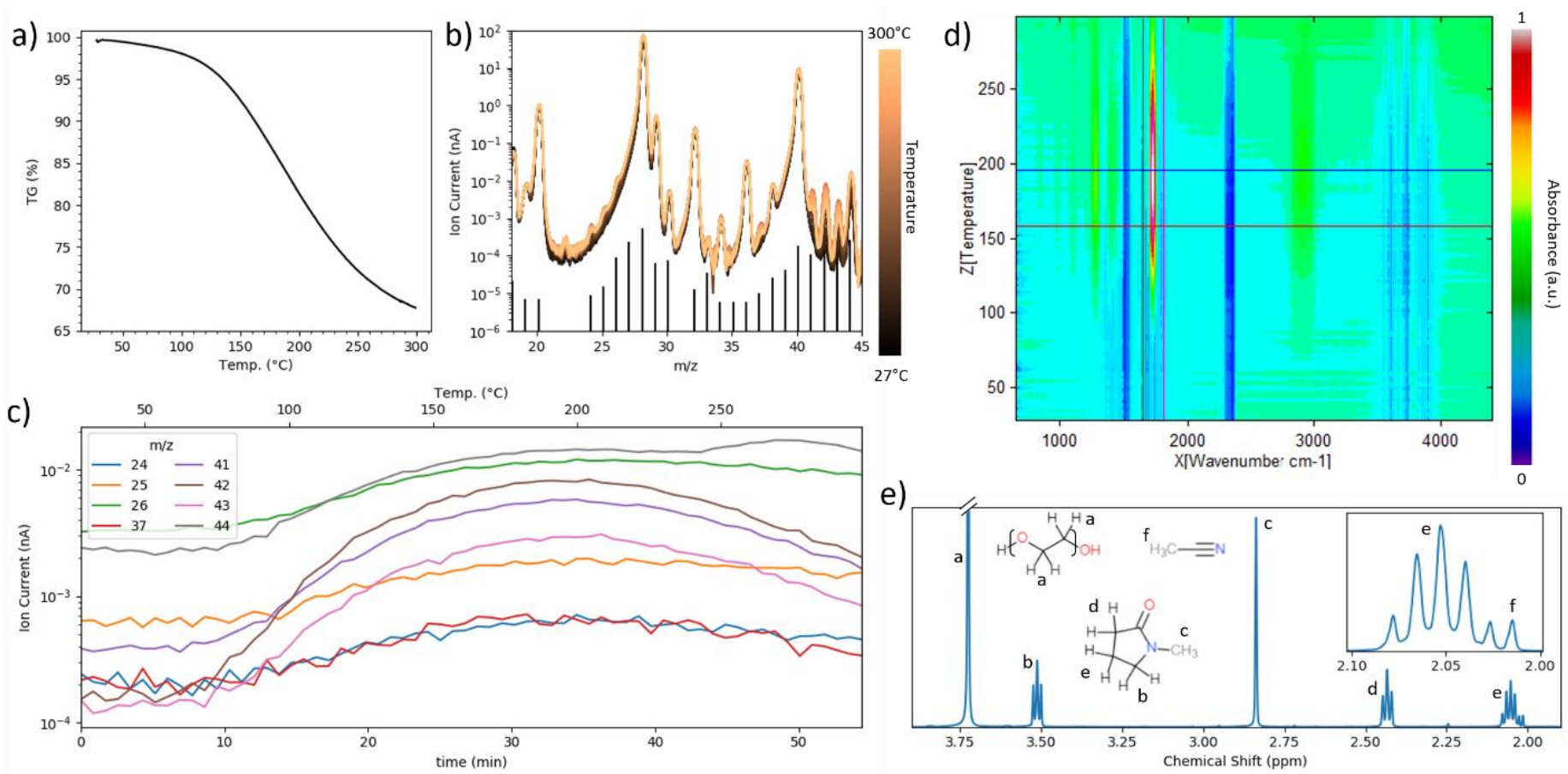

Figure 3: (a) TGA of a film with EO:LiTFSI of 4:1 showing mass percent as a function of temperature. (b) Analog scan mass spectra showing ion current vs mass/charge $(\mathrm{m} / \mathrm{z})$ of off-gas from TGA experiment in (a). The black bars are the standard mass spectra of NMP from NIST database. ${ }^{31}$ (c) Ion current of selected transient $\mathrm{m} / \mathrm{z}$ peaks from (b) that are attributed to NMP. (d) Contour plot FTIR spectra from TGA off-gas showing the evolution of absorbance as a function of wavenumber and temperature. (e) ${ }^{1} \mathrm{H}$ NMR spectrum of $\mathrm{P}(\mathrm{EO})_{4}: \mathrm{LiTFSI}\left(\mathrm{EO} / \mathrm{Li}^{+}\right.$ratio $\left.=4: 1\right)$ electrolyte dissolved in $\mathrm{D}_{2} \mathrm{O}$ $(23 \mathrm{mg} / \mathrm{mL})$. Inset shows an expanded view of a selected range.

addition, it has been demonstrated that as little as $5 \mathrm{wt} . \%$ NMP in PEO-based electrolytes acts as a plasticizer and increases the $\mathrm{Li}^{+}$ionic conductivity. ${ }^{35}$ Also, residual N,Ndimethylformamide (DMF) was also observed to be trapped in gel electrolytes based on poly(vinyl chloride) poly(ethylmethacrylate) blends for $\mathrm{Zn}^{2+}$ ionic conductivity. ${ }^{36}$ Furthermore, residual NMP in poly(vinylidene fluoride-co-hexafluoropropylene)-based gel electrolytes showed an enhanced $\mathrm{Zn}^{2+}$ ionic conductivity. ${ }^{37}$ Nairn et al. demonstrated that composite electrolytes of ceramic $\quad \mathrm{Li}_{1.3} \mathrm{Al}_{0.3} \mathrm{Ti}_{1.7}\left(\mathrm{PO}_{4}\right)_{3}$ and polyetherurethane: $\mathrm{LiCF}_{3} \mathrm{SO}_{3}$ when exposed to DMF, acetonitrile, or water vapors showed enhanced ionic conductivity "beyond simple plasticization of the polymer" by improving the surface contact between the polymer and the ceramic. ${ }^{38}$ We have discovered, albeit unintentionally, a gel electrolyte with a molar composition of $65.0 \% \mathrm{PEO}$, $16.25 \%$ LiTFSI, $17.66 \% \mathrm{NMP}$, and $1.1 \%$ acetonitrile that is completely amorphous and has high room temperature ionic conductivity. Considering the literature precedent that polymer electrolytes containing residual solvent molecules improve the contact between the polymer and ceramic materials, ${ }^{38}$ we sought to explore the use of these gel electrolytes as interfacial modification layers for LLZO and Li metal.

$L L Z O / L i$ interfacial modification.- Symmetric $\mathrm{Li} / \mathrm{Li}$ cells were assembled with a dense c-LLZO pellet as a solid-state electrolyte. PEO:LiTFSI (4:1) films were transfer coated onto lithium metal prior to assembly. The cell was warmed up to $76^{\circ} \mathrm{C}$ or $96^{\circ} \mathrm{C}$ and EIS was recoded, the cell was cooled back down to $39^{\circ} \mathrm{C}$ and EIS was recorded intermittently. Nyquist plots of a Li/c-LLZO/Li cell and a $\mathrm{Li} / \mathrm{PEO} / \mathrm{c}-\mathrm{LLZO} / \mathrm{PEO} / \mathrm{Li}$ cell with EIS measured at $70^{\circ} \mathrm{C}$ and $39^{\circ} \mathrm{C}$ are shown in Fig. $4 \mathrm{a}$ and $4 \mathrm{~b}$ respectively; insets show expanded views of the PEO modified cells. It is qualitatively clear from the Nyquist plots that the total impedance is greatly reduced at both $70^{\circ} \mathrm{C}$ and $39^{\circ} \mathrm{C}$ when the $\mathrm{Li} / \mathrm{c}-\mathrm{LLZO}$ interface is modified with PEO:LiTFSI (4:1) film. The EC model used to fit the data from a Li/c$\mathrm{LLZO} / \mathrm{Li}$ cell is shown in Fig. $4 \mathrm{c}$, where $\mathrm{R}_{\text {c-LLZO }}$ is the bulk electrolyte resistance, $\mathrm{R}_{\mathrm{c}-\mathrm{LLZO} / \mathrm{Li}}$ and $\mathrm{CPE}_{\mathrm{c}-\mathrm{LLZO} / \mathrm{Li}}$ are the charge transfer resistance and double-layer capacitance of the c-LLZO/Li interface, and $\mathrm{W}$ is Warburg-type diffusional impedance. For a PEO modified cell the EC 
model shown in Fig. 4d was used where $\mathrm{R}_{\mathrm{Li} / \mathrm{PEO}}$ and $\mathrm{CPE}_{\mathrm{Li} / \mathrm{PEO}}$ are the charge transfer resistance and doublelayer capacitance of the $\mathrm{Li} / \mathrm{PEO}$ interface, and $\mathrm{R}_{c-L L Z O / P E O}$ and $\mathrm{CPE}_{\mathrm{cLLZZO} / \mathrm{PEO}}$ are the charge transfer resistance and double-layer capacitance of the Li/PEO interface. This

a)

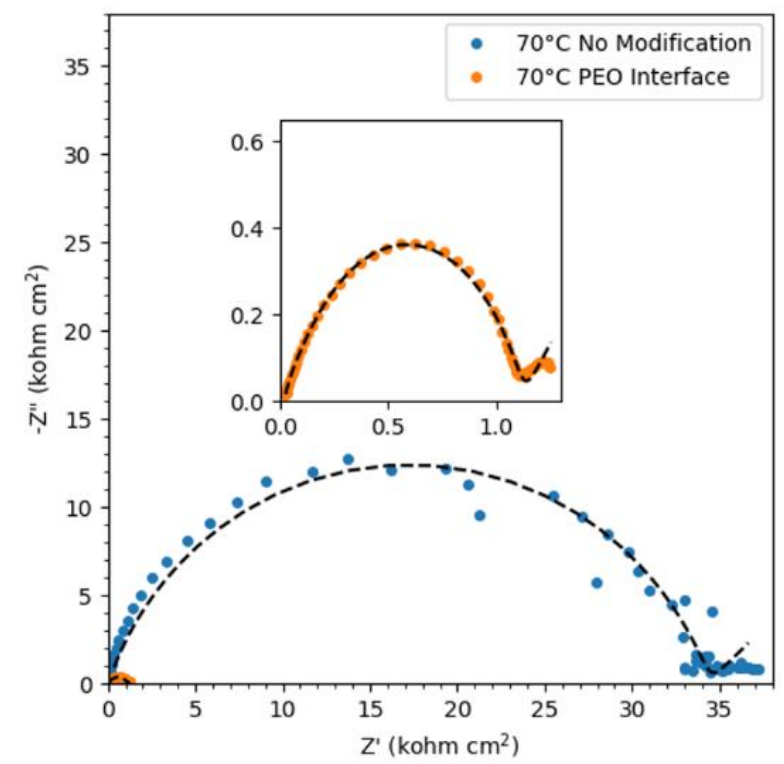

b)

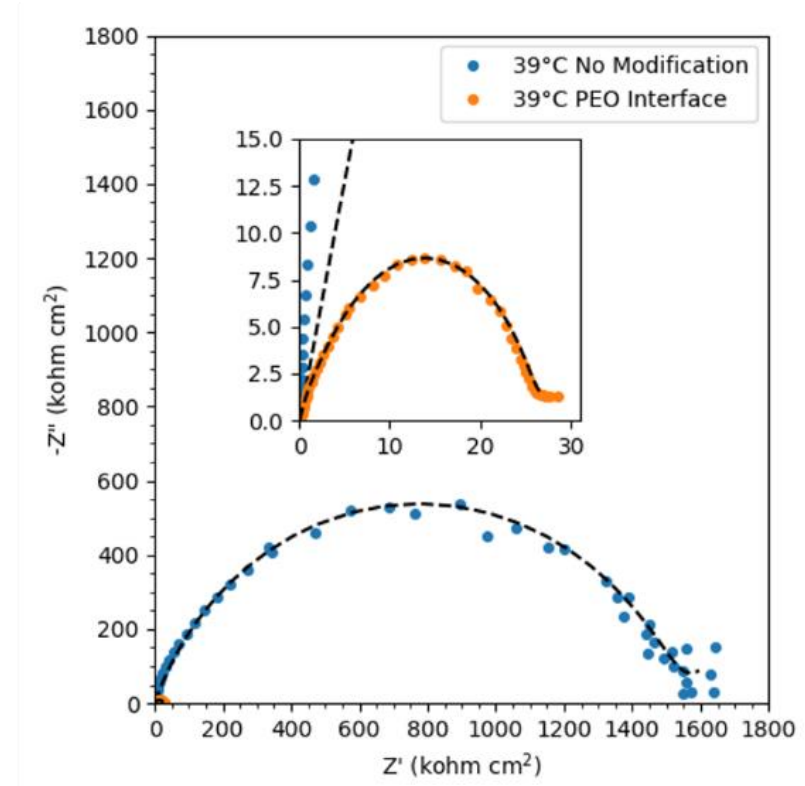

interpretation of the spectra is consistent with that by $\mathrm{Hu}$ and co-workers. ${ }^{22}$

To calculate the total interfacial resistance $\left(R_{\text {int }}\right) R_{c}$ $\mathrm{LLZO/Li}$ and $\mathrm{R}_{\mathrm{Li} / \mathrm{PEO}}$ are summed and halved due to the two identical interfaces in the symmetrical cell. The results of

c)
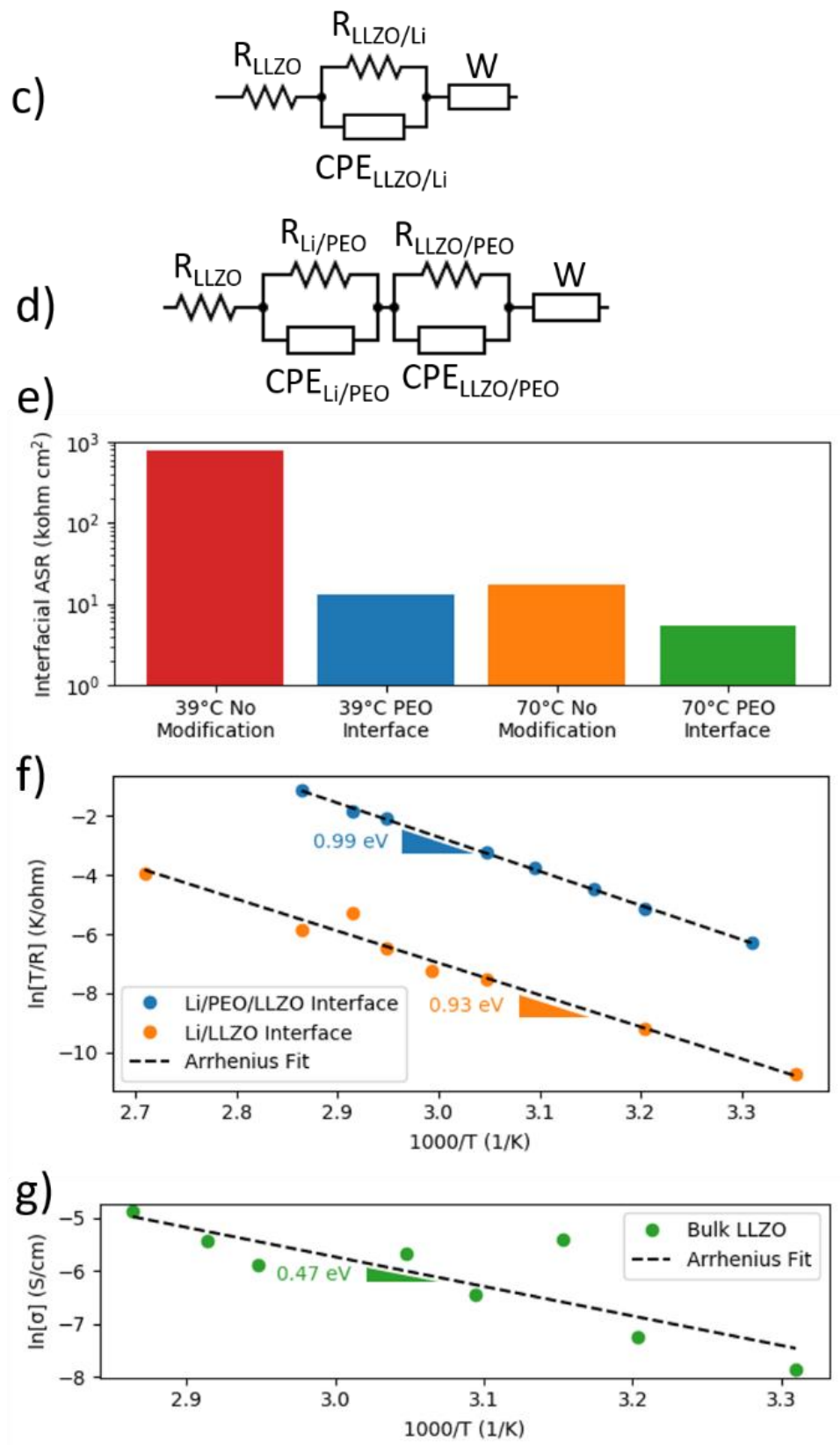

Figure 4: Nyquist plots of EIS results of symmetric Li cells with c-LLZO electrolyte with and without PEO:LiTFSI (4:1) modification layer at (a) $70^{\circ} \mathrm{C}$ and (b) $39^{\circ} \mathrm{C}$; insets show expanded view of $\mathrm{PEO}$ modified cells impedance. Equivalent circuit used to model (c) Li/c-LLZO/Li cell and (d) Li/PEO/c-LLZO/PEO/Li cell. (e) Plot of the interfacial ASR with and without PEO:LiTFSI (4:1) modification layer at $70^{\circ} \mathrm{C}$ and $39^{\circ} \mathrm{C}$. (f) Arrhenius-type analysis of interfacial impedance of Li/c-LLZO and $\mathrm{Li} / \mathrm{PEO} / \mathrm{c}-\mathrm{LLZO}$ interfaces. (g) Arrhenius-type analysis of c-LLZO bulk conductivity. 
interfacial area specific resistance (ASR) are summarized in Fig. 4e. At $39^{\circ} \mathrm{C}$, the interfacial ASR decreased from 765.0 kohm $\mathrm{cm}^{2}$ to $13.05 \mathrm{kohm} \mathrm{cm}^{2}$ with PEO interface modification, a 58 times reduction in resistance. At $70^{\circ} \mathrm{C}$, the interfacial ASR decreased from $17.2 \mathrm{kohm} \mathrm{cm}{ }^{2}$ to 5.5 kohm $\mathrm{cm}^{2}$ with PEO interface modification, a 3 times reduction in resistance. These results indicate that the reduction in interfacial ASR with the use of a PEO interface modification layer is much more profound at lower temperatures. Therefore, this material is a much more promising interfacial modification layer because it can be used in cells without high temperature requirements typical in other polymer electrolyte containing batteries. The $E_{A}$ for the interfacial charge transfer was calculated by plotting $T / R_{\text {int }}$ vs $1000 / T$ (Fig. 4f), and fitting the data to the linearized Arrhenius-type equation (Eq. 8):39

$$
T / \mathrm{R}_{\text {int }}=A \exp \left(-\frac{E_{A}}{k_{b} T}\right)
$$

where $k_{b}$ is Boltzmann's constant. The interfacial resistance is approximately two orders of magnitude smaller for the PEO modified cell. The activation energy for interfacial charge transfer was similar for both cells, $E_{A}=0.99 \mathrm{eV}$ and, $E_{A}=0.93 \mathrm{eV}$ for the PEO modified and unmodified cells respectively. The relatively high activation energy could indicate the formation of a thin interphase layer which is not highly conductive. The bulk conductivity of c-LLZO was found from fitted values for $\mathrm{R}_{\text {c-LLZO }}$ to be $\sigma=3.87 \times 10^{-4}$ $\mathrm{S} / \mathrm{cm}$, and $\sigma=7.62 \times 10^{-3} \mathrm{~S} / \mathrm{cm}$ at $29^{\circ} \mathrm{C}$ and $76^{\circ} \mathrm{C}$ respectively. An Arrhenius analysis was also performed on the c-LLZO conductivity data using Eq. 9:

$$
\sigma=A \exp \left(-\frac{E_{A}}{R T}\right)
$$

yielding an activation energy of $E_{A}=0.47 \mathrm{eV}$, which is consistent with reported values.

The pseudo-capacitance values calculated from the fitted CPEs from Eq. 5 for the interfacial impedance for unmodified c-LLZO/Li interface was on the order of a nF, whereas the capacitance values for PEO modified interfaces were approximately two orders of magnitude greater. The origin of the increase in capacitance is hypothesized to arise from ion accumulation in the polymer layer. The impact on the introduced capacitance was evaluated by using a lumped circuit model, ${ }^{40}$ for the $\mathrm{Li} / \mathrm{c}-\mathrm{LLZO} / \mathrm{Li}$ cell defined by Eq. 10 and Eq. 11:

$$
\begin{aligned}
& V(t)=I \times\left(\mathrm{R}_{\text {LLZO }}+\mathrm{R}_{\text {Li/LLZO }}\right)-I \times\left(\mathrm{R}_{\text {LLZO }}+\right. \\
& \left.\mathrm{R}_{\text {Li/LLZO }}\right) \times e^{-t / \tau} \\
& \tau=(10) \\
& \left.\mathrm{C}_{\text {Li/LLZO }}\right) \times\left(\mathrm{R}_{\text {LLZO }}+\mathrm{R}_{\text {Li/LLZO }}\right)
\end{aligned}
$$

and for the $\mathrm{Li} / \mathrm{PEO} / \mathrm{c}-\mathrm{LLZO} / \mathrm{PEO} / \mathrm{Li}$ cell defined by Eq. 12 and Eq. 13:

$$
\begin{aligned}
& V(t)=I \times\left(\mathrm{R}_{\mathrm{LLZO}}+\mathrm{R}_{\mathrm{Li} / \mathrm{PEO}}+\mathrm{R}_{\mathrm{PEO} / \mathrm{LLZO}}\right)-I \times \\
& \left(\mathrm{R}_{\mathrm{LLZO}}+\mathrm{R}_{\mathrm{Li} / \mathrm{PEO}}+\mathrm{R}_{\mathrm{PEO} / \mathrm{LLZO}}\right) \times e^{-t / \tau}(12) \\
& \tau=\left(\mathrm{C}_{\mathrm{Li} / \mathrm{PEO}}+\mathrm{C}_{\mathrm{PEO} / \mathrm{LLZO}}\right) \times\left(\mathrm{R}_{\mathrm{LLZO}}+\right. \\
& \left.\frac{1}{\frac{1}{\mathrm{R}_{\mathrm{Li} / \mathrm{PEO}}}+\frac{1}{\mathrm{R}_{\mathrm{PEO} / \mathrm{LLZO}}}}\right)
\end{aligned}
$$

where $V(t)$ is the time dependent potential, $I$ is the applied current, $\tau$ is the RC time constant. The time constant for symmetric cells with and without $\mathrm{PEO}$ layer at $70^{\circ} \mathrm{C}$ was calculated to be $\tau=40 \mu$ s and $\tau=88 \mu$ s respectively. Thus, the time constant for the cell with PEO is approximately half that of the unmodified cell even though the capacitance is two orders of magnitude greater due to the reduction in resistance. The overpotential, at a current $I=25 \mu \mathrm{A}$, was calculated by evaluating Eq. 10 and Eq. 12 at times (t) several orders of magnitude greater than $\tau$. The overpotentials for symmetric cells with and without PEO layer at $70^{\circ} \mathrm{C}$ was calculated to be $V=55.7 \mathrm{mV}$ and $V=$ $1.71 \mathrm{~V}$ respectively.

Symmetrical Cell Cycling.- Symmetric cells fabricated with PEO:LiTFSI (4:1) interfacial modification layers were cycled at $55^{\circ} \mathrm{C}$ at a current of $25 \mu \mathrm{A}(0.05$ $\left.\mathrm{mA} / \mathrm{cm}^{2}\right)$ for $30 \mathrm{~min}\left(0.025 \mathrm{mAh} / \mathrm{cm}^{2}\right)$ on each charge and discharge for 100 cycles, followed by of $25 \mu \mathrm{A}$ for $2 \mathrm{hr}(0.1$ $\left.\mathrm{mAh} / \mathrm{cm}^{2}\right)$ on each charge and discharge for 100 cycles. Fig. $5 \mathrm{a}$ shows the potential profile vs time for 200 cycles. Selected charge and discharge potential profiles are expanded in Fig. 5b-d reveal that there is no change in the overpotential $(199 \mathrm{mV})$ after cycling at $0.025 \mathrm{mAh} / \mathrm{cm}^{2}$ and a gradual increase to $222 \mathrm{mV}$ when cycling at $0.1 \mathrm{mAh} / \mathrm{cm}^{2}$ for an additional 100 cycles. This indicates that the $\mathrm{Li} / \mathrm{PEO}$ and $\mathrm{Li} / \mathrm{c}-\mathrm{LLZO}$ interfaces are relatively stable over 100 cycles and showed a small increase of $23 \mathrm{mV}$ after a total of 200 total cycles. EIS was recorded before and after cycling at $55^{\circ} \mathrm{C}$, the Nyquist plot and Bode plot is shown in Fig. 5e and Fig. $5 \mathrm{f}$ respectively. EIS data was fit using the EC model in Fig. 4d and is shown in black dashed lines. The results show a reduction in the interfacial ASR from $1.14 \mathrm{kohm} \mathrm{cm}^{2}$ to $0.85 \mathrm{kohm} \mathrm{cm}^{2}$ after the first 100 cycles at 0.025 $\mathrm{mAh} / \mathrm{cm}^{2}$ and then a slight increase to $1.02 \mathrm{kohm} \mathrm{cm}^{2}$ after cycling for an additional 100 cycles at $0.1 \mathrm{mAh} / \mathrm{cm}^{2}$. This indicates a stabilization and improvement of the interface with initial cycling followed by a growth of the SEI after cycling at higher current density. Hence, it indicates that the presence of solvents such as NMP and acetonitrile are not 

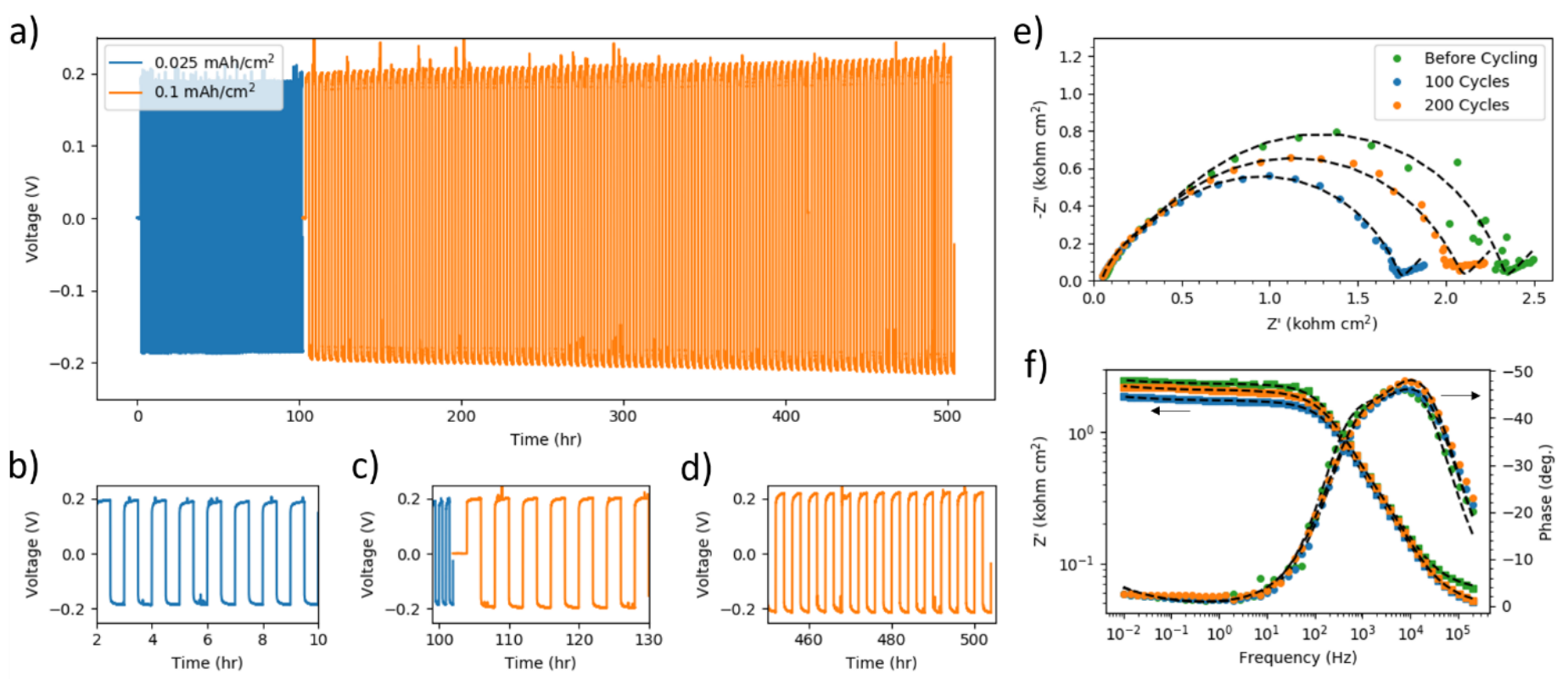

Figure 5: (a) Voltage profile vs time for a Li/PEO/LLZO/PEO/Li cell cycled at $0.025 \mathrm{mAh} / \mathrm{cm}^{2}$ (blue) and $0.1 \mathrm{mAh} / \mathrm{cm}^{2}$ (orange). (b-d) Selected expansion of voltage vs time profiles. (e) Nyquist plots and (f) Bode plots of EIS results for a $\mathrm{Li} / \mathrm{PEO} / \mathrm{LLZO} / \mathrm{PEO} / \mathrm{Li}$ cell before cycling, after cycling at $0.025 \mathrm{mAh} / \mathrm{cm}^{2}$ for 100 cycles, and after cycling at 0.01 $\mathrm{mAh} / \mathrm{cm}^{2}$ for an additional 100 cycles.

readily reacted at $\mathrm{Li}$ metal in a catastrophic way. 29,30 This is likely due to strong ion-solvent interactions which prevent the solvent from reacting too rapidly with Li metal. After an additional 100 cycles at $0.1 \mathrm{mAh} / \mathrm{cm}^{2}$ the interfacial ASR increased to $1.02 \mathrm{kohm} \mathrm{cm}^{2}$. The predicted overpotentials, using Eq. 12, from fitted EIS data is $173 \mathrm{mV}$ and $208 \mathrm{mV}$ for measurements taken after 100 and 200 cycles, compared to $199 \mathrm{mV}$ and $222 \mathrm{mV}$ from galvanostatic cycling measurements. The fitted values of EIS data would correspond to an overpotential increase of $35 \mathrm{mV}$ compared to the measured value of $23 \mathrm{mV}$ from the cycling overpotential.

\section{Conclusions:}

In this study, it was shown that introducing a thin gel polymer electrolyte interlayer to conformally coat solid electrolytes can improve the interface wettability of Li metal anode and thus reduce the interfacial resistance. We showed that strong interactions between LiTFSI and solvents such as acetonitrile and NMP can provide a plasticizing affect. Thin, less than 20 microns, polymer films were prepared with various $\mathrm{EO} / \mathrm{Li}^{+}$molar ratios ranging from $30 / 1$ to $4 / 1$. We found that the more LiTFSI that was added into PEO the more solvent was incorporated. Thus, there is likely strong ion-solvent interactions which caused solvent incorporation and prevented it from being evaporated during film drying under heat and vacuum. We used state- of-the-art analytical techniques including TGA-MS/FTIR, and NMR to quantify the amount of residual solvent molecules. We reported a gel electrolyte with a molar composition of $65.0 \%$ PEO, $16.25 \%$ LiTFSI, $17.66 \%$ NMP, and $1.1 \%$ acetonitrile which exhibited high room temperature $\mathrm{Li}^{+}$conductivity of $2.9 \times 10^{-4} \mathrm{~S} / \mathrm{cm}$. We investigated the electrochemical behavior of the modified $\mathrm{Li}-\mathrm{LLZO}$ interface using symmetric $\mathrm{Li} / \mathrm{Li}$ cells with and without the presence of the gel PEO-based interlayer. At $39^{\circ} \mathrm{C}$, the interfacial ASR decreased from $765.0 \mathrm{kohm} \mathrm{cm}^{2}$

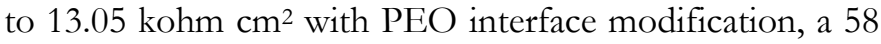
times reduction in resistance. At $70^{\circ} \mathrm{C}$, the interfacial ASR

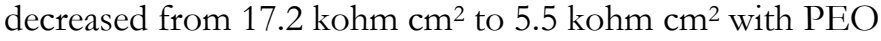
interface modification, a 3 times reduction in resistance. Cells were successfully cycled at $55{ }^{\circ} \mathrm{C}$ for 200 cycles. The results showed a reduction in the interfacial ASR from 1.14

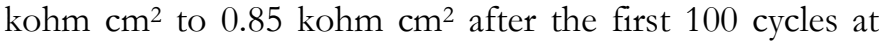
$0.025 \mathrm{mAh} / \mathrm{cm}^{2}$ and then a slight increase to $1.02 \mathrm{kohm} \mathrm{cm}$ after cycling for an additional 100 cycles at $0.1 \mathrm{mAh} / \mathrm{cm}^{2}$. The incorporation of highly conductive gel electrolyte interlayers is a cost-effective, scalable approach to further advance the development of all-solid-state lithium metal batteries. As acetonitrile and NMP tend to react with metallic lithium, alternative "plasticizers" with superior electrochemical behavior are presently being developed.

\section{Acknowledgements:}


The authors would like to acknowledge Caterpillar Ventures for funding. DSC, XRD, TGA-MS/FTIR work was performed at the UC Irvine Materials Research Institute (IMRI). NMR was performed by Dr. Phillip Dennison at the UC Irvine Nuclear Magnetic Resonance Spectroscopy Facility.

\section{References:}

1. J.-M. Tarascon, M. Armand, Nature, 414, 359-367 (2001).

2. J. B. Goodenough, Y. Kim, Chem. Mater., 22, 587-603 (2010).

3. M. Armand, J.-M. Tarascon, Nature, 451, 652-657 (2008).

4. W. Xu, J. Wang, F. Ding, X. Chen, E. Nasybulin, Y. Zhang, J.-G. Zhang, Energy Environ. Sci., 7, 513-537 (2014).

5. K. Xu, Chem. Rev., 114, 11503-11618 (2014).

6. P. G. Bruce, S. A. Freunberger, L. J. Hardwick, J.-M. Tarascon, Nat. Mater., 11, 19-29 (2011).

7. M. Golozar, A. Paolella, H. Demers, S. Bessette, M. Lagacé, P. Bouchard, A. Guerfi, R. Gauvin, K. Zaghib, Nat. Commun., 1-9 (2019).

8. A. Manthiram, X. Yu, S. Wang, Nat. Rev. Mater., 2, 1-16 (2017).

9. Z. Peng, S. A. Freunberger, L. J. Hardwick, Y. Chen, V. Giordani, F. Bardé, P. Novák, D. Graham, J.-M. Tarascon, P. G. Bruce, Angew. Chemie - Int. Ed., 50 (2011).

10. V. Giordani, D. Tozier, H. Tan, C. M. Burke, B. M. Gallant, J. Uddin, J. R. Greer, B. D. McCloskey, G. V. Chase, D. Addison, J. Am. Chem. Soc., 138 (2016).

11. W. Walker, V. Giordani, J. Uddin, V. S. Bryantsev, G. V. Chase, D. Addison, J. Am. Chem. Soc., 135 (2013).

12. K. Takada, Acta Mater., 61, 759-770 (2013).

13. J. W. Fergus, J. Power Sources, 195, 4554-4569 (2010).

14. R. Murugan, V. Thangadurai, W. Weppner, Angew. Chemie - Int. Ed. Chem. Int., 46, 7778-7781 (2007).

15. S. Afyon, F. Krumeich, J. L. M. Rupp, J. Mater. Chem. A, 3, 18636-18648 (2015).

16. A. Sharafi, C. G. Haslam, R. D. Kerns, J. Wolfenstine, J. Sakamoto, J. Mater. Chem. A, 5, 21491-21504 (2017).

17. S. Yu, R. D. Schmidt, R. Garcia-Mendez, E. Herbert, N. Dudney, J. B. Wolfenstine, J. Sakamoto, D. J. Siegel, Chem. Mater., 28, 197-206 (2016).
18. J. Wolfenstine, H. Jo, Y.-H. Cho, I. N. David, P. Askeland, E. D. Case, H. Kim, H. Choe, J. Sakamoto, Mater. Lett., 96, 117-120 (2013).

19. K. Fu, Y. Gong, Z. Fu, H. Xie, Y. Yao, B. Liu, M. Carter, E. D. Wachsman, L. Hu, Angew. Chemie - Int. Ed., 56, 14942 14947 (2017).

20. N. Delaporte, A. Guerfi, H. Demers, H. Lorrmann, A. Paolella, K. Zaghib, ChemistryOpen, 8, 192-195 (2019).

21. W. Zhou, S. Wang, Y. Li, S. Xin, A. Manthiram, J. B. Goodenough, J. Am. Chem. Soc., 138, 9385-9388 (2016).

22. B. Liu, Y. Gong, K. Fu, X. Han, Y. Yao, G. Pastel, C. Yang, H. Xie, E. D. Wachsman, L. Hu, ACS Appl. Mater. Interfaces, 9, 18809-18815 (2017).

23. G. T. Hitz, D. W. McOwen, L. Zhang, Z. Ma, Z. Fu, Y. Wen, Y. Gong, J. Dai, T. R. Hamann, L. Hu, E. D. Wachsman, Mater. Today, 22, 50-57 (2019).

24. B. Liu, L. Zhang, S. Xu, D. W. McOwen, Y. Gong, C. Yang, G. R. Pastel, H. Xie, K. Fu, J. Dai, C. Chen, E. D. Wachsman, L. Hu, Energy Storage Mater., 14, 376-382 (2018).

25. F. Huang, W. Liu, P. Li, J. Ning, Q. Wei, Materials (Basel)., 9 (2016).

26. M. D. Murbach, D. T. Schwartz, Electrochem. Soc. Interface, 28, 51-54 (2019).

27. S. K. Fullerton-Shirey, J. K. Maranas, Macromolecules, 42, 2142-2156 (2009).

28. K. M. Diederichsen, H. G. Buss, B. D. McCloskey, Macromolecules, 50, 3831-3840 (2017).

29. Y. Yamada, K. Furukawa, K. Sodeyama, K. Keitaro, M. Yaegashi, Y. Tateyama, A. Yamada, J. Am. Chem. Soc., 136, 5039-5046 (2014).

30. B. Commarieu, A. Paolella, S. Collin-Martin, C. Gagnon, A. Vijh, A. Guerfi, K. Zaghib, J. Power Sources, 436, 226852 (2019).

31. W. E. Wallace, "Infrared Spectra" in NIST Chemistry WebBook NIST Standard Reference Database Number 69 P. J. Linstrom, W. G. Mallard, Editors, National Institute of Standards and Technology, Gaithersburg MD, 20899, (2017).

32. D. Banfi, L. Patiny, Chimia (Aarau)., 62, 280-281 (2008).

33. J. Chatterjee, T. Liu, B. Wang, J. P. Zheng, Solid State Ionics, 181, 531-535 (2010).

34. G. Ek, F. Jeschull, T. Bowden, D. Brandell, Electrochim. 
Acta, 246, 208-212 (2017).

35. C. Kim, G. Lee, K. Liou, K. S. Ryu, S. G. Kang, S. H. Chang, Solid State Ionics, 123, 251-257 (1999).

36. S. P. Candhadai Murali, A. S. Samuel, J. Appl. Polym. Sci., 136, 1-14 (2019).

37. J. P. Tafur, F. Santos, A. J. Fernández Romero, Membranes (Basel)., 5, 752-771 (2015).
38. K. M. Nairn, A. S. Best, P. J. Newman, D. R. MacFarlane, M. Forsyth, Solid State Ionics, 121, 115-119 (1999).

39. A. Sharafi, H. M. Meyer, J. Nanda, J. Wolfenstine, J. Sakamoto, J. Power Sources, 302, 135-139 (2016).

40. L. Zhang, H. Peng, Z. Ning, Z. Mu, C. Sun, Appl. Sci., 7 (2017). 